ISSN 0258-7122

Bangladesh J. Agril. Res. 35(1) : 101-112, March 2010

\title{
TECHNICAL INEFFICIENCY OF WHEAT PRODUCTION IN SOME SELECTED AREAS OF BANGLADESH
}

\author{
M. KAMRUL HASAN ${ }^{1}$ AND S. M. FAKHRUL ISLAM ${ }^{2}$
}

\begin{abstract}
The main objective of the study was to identify and analyze the inefficiency and yield gaps of wheat production in Bangladesh. The study employed farm level cross sectional data from three major wheat growing areas of Bangladesh. Yield of wheat was found to vary across locations and farm categories. The average technical inefficiency of wheat production in Bangladesh is 16. This indicates a good potential for increasing wheat output by 16 percent with the existing technology and levels of inputs. Education and training on wheat of the farm operators was found to have significant effect on yield and technical efficiency of wheat production.
\end{abstract}

Keywords : Technical inefficiency, wheat production, yield gaps.

\section{Introduction}

Wheat is one of the main cereal crops in Bangladesh. Starting with an area of 0.126 million hectares, and production of 0.103 million metric tons in 1971, the area and production increased to 0.83 million hectares and 1.84 million metric tons, respectively, in 2000 (Hasan, 2006). The yield also increased from $0.86 \mathrm{t} / \mathrm{ha}$ to $2.21 \mathrm{t} /$ ha during the period. This increased area, production, and yield of wheat spurred mainly because of the introduction of modern seed-water-fertilizer technologies. After reaching its highest area (0.88 million hectares) and production (1.91 million tons) in 1999; the area and production was found to be decreasing during next seven years. In 2006, the area decreased to 0.48 million hectares and production to 0.74 million metric tons. The yield was also reduced to $1.6 \mathrm{t} / \mathrm{ha}$ (BBS, 2007). On the contrary, farm level expected yield of high yielding wheat varieties was found to be 3.5-5.1 t/ha (Hasan, 2006). Performances of varieties vary significantly from research station to farmers' field, even wide variation in yields is observed among the farmers. Variation in different factors of production package is mainly responsible for such kind of yield gap. Amount and quality of different inputs used and other management vary from one farmer to another. Thus the potential yield level at farmers' field is not achieved in many cases. Farmers cultivating HYVs of different crops also do not follow the recommended packages. As a result, the differences between potential yield and yield under farmers' practice are widened. The management

${ }^{1}$ Senior Scientific Officer, Planning and Evaluation Division, BARI, Joydebpur, Gazipur1701, ${ }^{2}$ Professor, Department of Agricultural Economics, BSMRAU, Joydebpur, Gazipur-1706, Bangladesh. 
practices and input use are likely to be influenced by various socio-agroeconomic factors, such as farmers' age, education, occupation, experience in farming, resource base, family size, access to information, physical infrastructure, demand of the family, market, etc. These factors influence farmers to adopt any technology fully or partially. It is possible to attain a higher yield of different crops by adopting modern practices and thus the yield gaps can be minimized in this way.

The socioeconomic constraints to higher production of wheat are of vital importance. The socioeconomic constraints may explain why farmers are not utilizing the practices and inputs identified as capable of raising yields. Therefore, planners and policy makers need information on the relative importance of various yield constraints so that they can allocate and redistribute the available resources for various researchable issues in order to augment productivity. There is a scope to increase the yield level by minimizing the yield gap. The technology that gives high yields on experiment stations may not give high yield in the less favourable environment that exists in a large part of the crop growing areas. There may also be components of experiment station technology that are not transferable to a farmer's field, named yield gap-I by Dc Datta et al.(1978). Yield gap-2 is the difference between the potential and actual yields in farmer's environments. By definition, this gap exists because farmers use inputs or practices that result in lower yields than those possible on their farms. The study will focus on the yield gap- 2 of wheat production in the selected areas.

The study was, therefore, designed to identify and analyze the possibilities for improving productivity of wheat by increasing the productive efficiency of wheat farmers of Bangladesh. However, the specific objective of the study was to identify and measure various factors associated with yield gaps and technical inefficiency of wheat farmers.

\section{Materials and Method}

\section{Source of data}

A multistage sampling procedure was followed to select wheat growing areas. In the first stage, three wheat growing districts i.e., Dinajpur, Rajshahi, and Jamalpur were chosen purposively considering the intensity of wheat area coverage among different regions. In the second stage, one upazila from each district and one union from each upazila were selected randomly. Finally, three mouzas (one from each union), namely Char Palisha Madhyapara from Char Banipakuri union of Melandah Upazila under Jamalpur district, Bhatgaon from Sundarpur union of Kaharol Upazila under Dinajpur district and Bhograil under Noahata union of Paba Upazila under Rajshahi district were selected randomly for this study. 
To collect primary data, a sampling frame of wheat growing holdings in the selected mouzas were constructed with the help of village leaders and record book of union council. These farm holdings were stratified into small ( 0.2 ha to $<$ $1.0 \mathrm{ha}$ ), medium (1.0 ha to <2.0 ha), and large ( 2.0 ha and above) as per classification of farm category followed in different studies (Karim, 1996; Hasan et al., 2002). For determining the sample size Fisher's measure of skewness formula (Fisher, 1958) was applied and an optimum number (Cochran, 1999) of 293 samples (Dinajpur-10l, Jamalpur-89, and Rajshahi-103) were chosen. A predesigned and pre-tested schedule was applied to collect data during November 2003 to June 2004.

\section{Analytical techniques}

\section{Technical inefficiency effect model}

The empirical Cobb-Douglas frontier production function for technical inefficiency effect can be expressed as follows:

$u_{i}=\delta_{0}+\delta_{1} \mathrm{Z}_{1 i}+\delta_{2} \mathrm{Z}_{2 i}+\delta_{3} \mathrm{Z}_{3 i}+\delta_{4} \mathrm{Z}_{4 i}+\delta_{5} \mathrm{Z}_{5 i}+\delta_{6} \mathrm{Z}_{6 i}+\delta_{7 \mathrm{Z}_{7 i}}+W_{i}$

where,

The $u_{i}$ 's are non-negative random variables, assumed to be independently distributed such that the technical inefficiency effect for the $i^{\text {th }}$ farmer, $u_{i}$, were obtained by truncation of normal distribution with mean zero and variance, $\sigma_{u}^{2}$, such that

$\mathrm{z}_{1 i}=$ Ln operated land of the i-th farm operator (ha)

$z_{2 i}$ Age of the i-th farm operator (years)

$z_{3 i}=$ Education level of the i-th farm operator (year of schooling)

$z_{4 i}=$ Experience in wheat farming of the i-th farm operator (years)

$z_{5 i}=$ Household size of the i-th farm operator (persons/household)

$z_{6 i}=$ Dummy for extension linkage of the $\mathrm{i}$-th farm operator $(1=$ yes, $0=$ otherwise)

$z_{7 i}=$ Dummy for wheat training of the i-th farm operator ( 1 yes, $0=$ otherwise)

$\delta$ 's are unknown parameters to be estimated

$\mathrm{W}_{1} \mathrm{~s}$ were unobservable random variables or classical disturbance term, which are assumed to be independently distributed, obtained by truncation of the normal distribution with mean zero and unknown variance, $\sigma^{2}$, such that $u_{i}$ is nonnegative.

The $\beta, \eta$ and $\delta$ coefficients are unknown parameters to be estimated, together with the variance parameters which are expressed in terms of 
$\sigma^{2}=\sigma_{u}^{2}+\sigma_{v}^{2}$

and $\gamma=\sigma_{u}^{2} / \sigma^{2}$

$\gamma$ is the ratio of variance of farm specific technical efficiency to the total variance of output and has a value between zero and one.

The estimates for all parameters of the inefficiency model (1) were estimated by using the Maximum Likelihood (ML) method. The econometric computer software package FRONTIER 4.1 (Coelli, 1996) was applied to estimate the parameters of stochastic frontier models using the ML method.

\section{Estimation of yield gap}

Yield gap may be defined as the difference between technically full efficient yield and observed yield. Therefore, yield gap was estimated by deducting observed yield from technically full efficient yield. In other words, yield gap is the amount which represents less yield due to technical inefficiency [(for detail see Hasan (2006)1.

\section{Results and Discussion}

\section{Yield gap due to technical inefficiency}

The yield gap that occurred due to technical inefficiency is presented in Table 1 . It was observed that mean technical inefficiency was 16 percent which caused $454 \mathrm{~kg} / \mathrm{ha}$ yield gap of wheat. The highest yield gap of wheat due to technical inefficiency was recorded with the farmers at Dinajpur (497 kg/ha) followed by that at Rajshahi (493 kg/ha) and Jamalpur (361 kg/ha) implying that Dinajpur farmers had more potential to increase yield than Jamalpur farmers with existing technology. According to farm categories, large and medium farmers had more potential to increase yield than small farmers with the existing technology.

Table 1. Yield gap of wheat due to technical inefficiency.

\begin{tabular}{l|c|c|c}
\hline $\begin{array}{c}\text { Location/Farm } \\
\text { category }\end{array}$ & $\begin{array}{c}\text { Mean technical } \\
\text { inefficiency (\%) }\end{array}$ & $\begin{array}{c}\text { Observed yield } \\
(\mathrm{kg} / \mathrm{ha})\end{array}$ & Yield gap (kg/ha) \\
\hline Locations: & & \\
\hline Dinajpur & 0.17 & 2493 & 497 \\
Jamalpur & 0.16 & 2189 & 361 \\
Rajshahi & 0.17 & 2477 & 493 \\
\hline Farm categories: & & 463 \\
\hline Large & 0.15 & 2532 & 463 \\
Medium & 0.16 & 2381 & 446 \\
Small & 0.16 & 2347 & $\mathbf{4 5 4}$ \\
\hline All farms & $\mathbf{0 . 1 6}$ & $\mathbf{2 3 9 5}$ & \\
\hline
\end{tabular}

Source: Hasan (2006, p. 201) 
To test whether there were significant differences in yield gaps among the locations and farm categories, an analysis of variance was carried out. Table 2 shows that there were significant differences in the yield gaps of the farmers between the locations, but within each location there was no significant difference in yield gaps between the farm categories.

Table 2. Analysis of variance of yield gap due to technical inefficiency among different locations and farm categories in wheat cultivation.

\begin{tabular}{|c|c|c|c|c|c|}
\hline Source of variation & Sum of Squares & $\begin{array}{l}\text { Degrees of } \\
\text { freedom }\end{array}$ & Mean Square & $\mathrm{F}$ & Significance \\
\hline Between locations & 658445.363 & 2 & 329222.682 & 20.039 & .000 \\
\hline Within locations & 4764508.909 & 290 & 16429.341 & & \\
\hline Total & 5422954.272 & 292 & & & \\
\hline $\begin{array}{l}\text { Between farm } \\
\text { categories }\end{array}$ & 17425.243 & 2 & 8712.621 & 0.467 & .627 \\
\hline $\begin{array}{l}\text { Within farm } \\
\text { categories }\end{array}$ & 5405529.029 & 290 & 18639.755 & & \\
\hline Total & 5422954.272 & 292 & & & \\
\hline
\end{tabular}

\section{Factors affecting farm-specific technical inefficiency}

The ML estimates of technical inefficiency effect models which show the best practice performance are presented in Table 3-5. The estimates of farm specific variables in those models which were responsible for technical inefficiency are discussed below:

Operated land: The coefficient of operated land is positive but not significant in the technical inefficiency model for wheat production (Table 3) which implied that technical inefficiency increases with the increase in operated land. That is, farmers with smaller farms are technically more efficient than farmers with larger operations. This corresponds to the argument which is made frequently for smaller farmers who tend to be more efficient in production than larger farmers in developing country. The coefficient of operated land is significantly negative for Dinajpur, insignificantly positive for Jamalpur and Rajshahi in the locationspecific technical inefficiency model (Table 4) which indicated that technical inefficiency decreases with the increase in operated land at Dinajpur. This may be due to the advantage of applying mechanical devices for land preparation in the larger wheat plots at Dinajpur. On the other hand, the coefficient of operated land for large farms were negative and that for medium and small farms were positive in the farm size-specific technical inefficiency model for wheat production (Table 5) but all were insignificant. 
Technical efficiency of farmers with respect to farm size was observed in many studies with various kinds of findings. It was observed from a number of studies (Rahman et al., 1999; Ajibefun et al., 2002) that there was a significant negative correlation with farm size and efficiency, others (Sharma et al., 1999; Rahman et al., 2000) observed significant positive correlation between farm size and efficiency. This difference of findings in different studies may be the outcome of farm sizes. Farm size itself was different for various studies.

Table 3. Maximum likelihood estimates of the technical inefficiency model for wheat.

\begin{tabular}{|c|c|c|c|c|}
\hline Independent variables & $\begin{array}{l}\text { Para- } \\
\text { meters }\end{array}$ & $\left|\begin{array}{c}\text { Co- } \\
\text { efficient }\end{array}\right|$ & $\begin{array}{c}\text { Standard } \\
\text { error }\end{array}$ & t-ratio \\
\hline Constant & $\delta_{0}$ & 0.173 & 0.068 & 2.56 \\
\hline Ln Operated land & $\delta_{1}$ & 0.0002 & 0.012 & 0.22 \\
\hline Farmer’s age (years) & $\delta_{2}$ & -0.0005 & 0.0006 & -1.18 \\
\hline Farmer's education (year of schooling) & $\delta_{3}$ & -0.005 & 0.002 & -2.81 \\
\hline Wheat farming experience (years) & $\delta_{4}$ & $-0.002 ”$ & 0.001 & -1.98 \\
\hline Household size (person/hh) & $\delta_{5}$ & -0.003 & 0.004 & -1.50 \\
\hline $\begin{array}{l}\text { Dummy for Extension linkage (1=Yes, } 0= \\
\text { otherwise) }\end{array}$ & $\delta_{6}$ & 0.007 & 0.008 & 1.04 \\
\hline Dummy for wheat training ( $1=$ Yes, $0=$ otherwise $)$ & $\delta_{7}$ & -0.006 & 0.026 & -0.45 \\
\hline \multicolumn{5}{|l|}{ Variance parameters } \\
\hline Sigma-squared & $\sigma^{2}$ & $0.005^{* *}$ & 0.001 & 8.746 \\
\hline Gamma & $\gamma$ & $1.000^{* *}$ & 0.006 & 175.03 \\
\hline Log likelihood function & & & 371.148 & \\
\hline
\end{tabular}

** and * indicate significant at $1 \%$ and $5 \%$ level of probability, respectively.

Farmers' age: The coefficient of farmers' age was negative but not significant in the technical inefficiency model for wheat production (Table 3) which implied that technical inefficiency effect decreases with the increase in age of farmers. The coefficients of farmers' age was positive for Dinajpur and negative for Jamalpur and Rajshahi in the location-specific technical inefficiency model for wheat production (Table 4), but all were insignificant. On the other hand, the coefficients of farmers' age were positive for large and negative for medium and small farm categories in the farm size-specific technical inefficiency model for wheat production (Table 5) but also all were insignificant.

Farmers with older age were technically more efficient was reported by Coelli and Battese (1996) and Rahman (2002). Llewelyn and Williams (1996) observed that technical efficiency increases upto a certain age level and then eventually declines. Ajibefun et al. (2002) and Miah (2001) observed a negative 
association with age of farmers and technical efficiency of rice farmers in Dominican Republic and Bangladesh, respectively. This indicates that age has mixed impact on efficiency and may be depending on crop and study area.

Table 4. Maximum likelihood estimates for parameters of location-specific technical inefficiency model for wheat.

\begin{tabular}{|c|c|c|c|c|}
\hline \multirow{2}{*}{$\begin{array}{c}\text { Independent } \\
\text { variables }\end{array}$} & \multirow{2}{*}{ Parameters } & \multicolumn{3}{|c|}{ Location } \\
\hline & & Dinajpur & Jamalpur & Rajshahi \\
\hline Constant & $\delta_{0}$ & $0.134 * *(0.046)$ & $0.262 *(0.125)$ & $0.214 *(0.110)$ \\
\hline Ln Operated land & $\delta_{1}$ & $-0.013 *(0.007)$ & $0.006(0.115)$ & $0.010(0.012)$ \\
\hline Farmers age (years) & $\delta_{2}$ & $0.0004(0.0007)$ & $-0.0003(0.002)$ & $-0.001(0.001)$ \\
\hline $\begin{array}{l}\text { Farmers education } \\
\text { (year of } \\
\text { schooling) }\end{array}$ & $\delta_{3}$ & $0.004^{* *}(0.0014)$ & $-0.004 *(0.002)$ & $0.007 * *(0.002)$ \\
\hline $\begin{array}{l}\text { Wheat farming } \\
\text { experience } \\
\text { (years) }\end{array}$ & $\delta_{4}$ & $-0.0008(0.0013)$ & $0.002 *(0.001)$ & $-0.002(0.002)$ \\
\hline $\begin{array}{l}\text { Household size } \\
\text { (person/hh) }\end{array}$ & $\delta_{5}$ & $-0.002(0.003)$ & $-0.003(0.043)$ & $-0.004(0.004)$ \\
\hline $\begin{array}{l}\text { Dummy for } \\
\text { Extension linkage } \\
\text { (1=Yes, } \\
0=\text { otherwise) }\end{array}$ & $\delta_{6}$ & $0.013(0.009)$ & $0.019(0.049)$ & $-0.012(0.022)$ \\
\hline $\begin{array}{l}\text { Dummy for wheat } \\
\text { training } \\
\text { (1=Yes, Ootherwise) }\end{array}$ & $\delta_{7}$ & $-0.001(0.016)$ & $-0.223(0.143)$ & $0.030 *(0.012)$ \\
\hline \multicolumn{5}{|l|}{ Variance parameters } \\
\hline Sigma-squared & $\sigma^{2}$ & $0001^{* *}(0.0004)$ & $0.005 * *(0.002)$ & $0.004^{* *}(0.001)$ \\
\hline Gamma & $\gamma$ & $1.000 * *(0.0378)$ & $0.996 * *(0.085)$ & $1.000 *(0.455)$ \\
\hline $\begin{array}{l}\text { Log likelihood } \\
\text { function }\end{array}$ & & 192.646 & 137.667 & 146.161 \\
\hline
\end{tabular}

** and * indicate significant at $1 \%$ and $5 \%$ level of probability, respectively. Figures in the parenthesis indicate standard error.

Farmers' education: The coefficient of farmers' education was negative and significant in the technical inefficiency model for wheat production (Table 3) which implied that technical inefficiency decreases with the increase in farmers' education. It may also be concluded that farmers with higher education tend to have lower inefficiency effects than farmers with lower education. That is, farmers with higher education were technically more efficient than farmers with 
lower education. It may be mentioned here that the average year of schooling of the sampled farmers was only 4.9 years.

The coefficient of farmers' education was negative and significant for all the three locations in the location-specific technical inefficiency model for wheat production (Table 4) which implied that technical inefficiency decreases with the increase in farmers' education in all the three locations. The coefficient of farmers' education was negative and significant for all the three farm categories in the farm size-specific technical inefficiency model for wheat production (Table 5), which also implied that technical inefficiency decreases with the increase in farmers' education for the large, medium, and small farms.

The results of some other studies revealed that the association between farmers' education and individual farm technical efficiency was quite mixed. Islam (2002) found significant positive relationship of farmers' education and technical efficiency for aromatic and fine rice growers in Bangladesh, but for coarse rice, he observed negative but non-significant relationship. Ajibefun $\boldsymbol{e} \boldsymbol{a l}$. (2002) and Khan and Alam (2003) observed significant positive correlation with education and efficiency. On the contrary, Miah (2001) and Rahman (2002) found significant negative relationship with education and efficiency.

Wheat farming experience: The coefficient of wheat farming experience was negative and significant at $5 \%$ level in the technical inefficiency model for wheat production (Table 3) which implied that technical inefficiency decreases with the increase in wheat farming experience. It may also be concluded that farmers with higher wheat farming experience tend to have lower inefficiency effects than farmers with lower wheat farming experience. This implied that performance of farmers with higher experience in wheat farming in adopting new technology was far better than less experienced farmers. The coefficient of wheat farming experience was negative for all the three locations but was found significant for only Jamalpur in the location-specific technical inefficiency model for wheat production (Table 4) which implied that technical inefficiency decreases with the increase in wheat farming experience. This may be due to the less wheat farming experience of the farmers in Jamalpur district compared to Dinajpur and Rajshahi. The coefficient of wheat farming experience was negative for all the three farm categories but was found significant for medium and small farms in the farm size-specific technical inefficiency model for wheat production (Table 5). This implied that technical inefficiency decreases with the increase in wheat farming experience for the medium and small farms significantly. 
Table 5. Maximum likelihood estimates for parameters of farm size-specific technical inefficiency model for wheat.

\begin{tabular}{|c|c|c|c|c|}
\hline \multirow{2}{*}{$\begin{array}{l}\text { Independent } \\
\text { variables }\end{array}$} & \multirow{2}{*}{ Parameters } & \multicolumn{3}{|c|}{ Farm category } \\
\hline & & Large & Medium & Small \\
\hline Constant & $\delta_{0}$ & $0.220(1.026)$ & $-0.259(0.602)$ & $0.0001(0.092)$ \\
\hline Ln Operated land & $\delta_{1}$ & $-0.041(0.156)$ & $0.072(0.103)$ & $0.007(0.032)$ \\
\hline Farmers age (years) & $\delta_{2}$ & $0.0001(0.002)$ & $-0.0003(0.00 !)$ & $-0.0002(0.001)$ \\
\hline $\begin{array}{l}\text { Farmers education } \\
\text { (year of schooling) }\end{array}$ & $\delta_{3}$ & $-0.003 *(0.002)$ & $0.002 *(0.001)$ & $-0.012 * *(0.004)$ \\
\hline $\begin{array}{l}\text { Wheat farming exp. } \\
\text { (years) }\end{array}$ & $\delta_{4}$ & $-0.002(0.008)$ & $-0.001 * 0.0005)$ & $-0.007 *(0.004)$ \\
\hline $\begin{array}{l}\text { Household size } \\
\text { (person/hh) }\end{array}$ & $\delta_{5}$ & $0.018(0.012)$ & $-0.019(0.010)$ & $-0.004(0.012)$ \\
\hline $\begin{array}{l}\text { Dummy for } \\
\text { Extension linkage } \\
\text { (l=Yes, } 0=\text { otherwise) }\end{array}$ & $\delta_{6}$ & $0.042(0.092)$ & $0.034(0.034)$ & $0.013(0.031)$ \\
\hline $\begin{array}{l}\text { Dummy for wheat } \\
\text { training (l=Yes, } \\
0=\text { otherwise) }\end{array}$ & $\delta_{7}$ & $-0.025 *(0.012)$ & $-0.006(0.044)$ & $-0.015(0.055)$ \\
\hline \multicolumn{5}{|l|}{ Variance parameters: } \\
\hline Sigma-squared & $\sigma^{2}$ & $0.007 * *(0.001)$ & $0.008 * *(0.001)$ & $0.008 * *(0.001)$ \\
\hline Gamma & $\gamma$ & $1.000(0.004)$ & $1.000 * *(0.001)$ & $0.985 * *(0.060)$ \\
\hline $\begin{array}{l}\text { Log likelihood } \\
\text { function }\end{array}$ & & 101.549 & 123.427 & 199.425 \\
\hline
\end{tabular}

** and * indicate significant at $1 \%$ and $5 \%$ level of probability, respectively. Figures in the parenthesis indicate standard error

This negative coefficient of wheat farming experience also corresponds with the negative coefficient of farmers' age in the technical inefficiency model i.e., technical inefficiency tends to decline with years of experience. This finding was in conformity with the findings of Islam (2003) and Khan and Alam (2003). Wilson et al. (1998) found producers with fewer years of experience to have achieved higher levels of technical efficiency.

Household size: The coefficient of household size was negative but not significant in the technical inefficiency model for wheat production (Table 3) which implied that technical inefficiency decreases with the increase in household size. That is, farmers with smaller family size were technically less efficient than farmers with larger family size. The coefficients of household size were positive for large farms and negative for medium and small farms, but all were insignificant in the farm size-specific technical inefficiency model for wheat production (Table 5) which implied that technical inefficiency increases with the increase in household size for the large farms, but technical inefficiency 
decreases with increase of household size for medium and small farms. Parikh and Shah (1994) observed that greater family size increased technical efficiency.

Extension linkage: The coefficient of dummy for extension linkage was positive but not significant in the technical inefficiency model for wheat production (Table 3). This implied that technical inefficiency was higher with the farmers who had link with extension agents than that of the farmers without extension linkage.

Though it is assumed that extension linkage should have a positive effect on technical efficiency by providing up-to-date information regarding modern technology than that of non- linkage farmers, in this particular case, no significant role was found due to very poor extension linkage with the farmers in the study areas. It was observed that 49.1 percent of the farmers had no linkage or contact with the extension agents, while only 21.2 percent had weekly contact with the extension agents. Regarding sources of agricultural information, most of the farmers depended on neighbours and relatives (79.9\%), while 45.1 percent on electronic media like radio and television and only 44 percent on extension agents like BS and others which also indicated the poor influence of government extension service.

Islam (2003) found that the visits of agricultural extension agents on the farm or farmers' visits to extension office played positive and statistically significant role in achieving frontier output.

Training on wheat: Training of farmers on any particular crop is important because it can improve farmers' skill regarding production practices and related aspects. A number of farmers in the study areas received training on wheat for I to 2 days mainly on production practices and seed storage in the household level. The coefficient of wheat training dummy was negative and significant in the technical inefficiency model for wheat production (Table 3) which implied that technical inefficiency effect decreases with farmers having training on wheat. It may also be concluded that farmers with training on wheat tended to have lower inefficiency effects than farmers without training. That is, farmers with training were technically more efficient than farmers without training.

The coefficients of wheat training dummy were negative for all the three locations but was found significant for Rajshahi in the location-specific technical inefficiency model for wheat production (Table 4) which implied that technical inefficiency effect decreases with the farmers who had training on wheat than the farmers without training at Rajshahi. The coefficient of wheat training dummy were negative for all the three farm categories but was found significant for only large farms in the farm-size specific technical inefficiency model for wheat production (Table 5) which implied that technical inefficiency decreases with the training on wheat for the large farms. 
The finding of this study is in conformity with the findings of Rajasekharan and Krishnamoorthy (1999) who found significant positive role of training on the technical efficiency for rubber farming.

\section{Conclusions}

The findings of the study indicated that the yield gap of wheat between best practice and average farmers can be reduced and efficiency of wheat production can be increased significantly by adopting a number of measures:

Average yield gap in wheat production is $454 \mathrm{~kg} / \mathrm{ha}$ which is derived from technical inefficiency. This amount of less yield can be recovered with existing technology and yield gap can be minimized by giving attention to the formal education, training on wheat technologies and wheat farming experience of the growers. The average technical inefficiency of wheat production in Bangladesh is 16 percent. This indicates a good potential for increasing wheat output by 16 percent with the existing technology and levels of inputs. Education and training on wheat of the farm operators was found to have significant effect on yield and technical efficiency of wheat production in the farm specific, location specific and farm size specific stochastic frontier production function models. Technical inefficiency decreases (i.e., efficiency increases) with the increase in education and training on wheat of farm operators. Thus, it is a priority issue to invest in public education to explore and develop human resources of farms. Formal training on wheat technology will also be an effective technique to improve farmers' efficiency.

\section{References}

Ajibefun, 1. A., G. E. Battese and A. G. Daramola. 2002. Determinants of technical efficiency in smaliholder food crop farming: Application of stochastic frontier production function. Quarterly Journal of InternationalAgriculture. 41(3): 225-240.

Cochran W. G. 1999. Sampling Techniques ( $3^{\text {rd }}$ Edn), John Willey \& Sons, New York, USA. Pp 39-44.

Coelli, T. and G. Battese. 1996. Identification of factors which influence the technical inefficiency of Indian farmers. Australian Journal of Agricultural Economics 40 (2): 103-128.

Coelli, T. J. 1996. A guide to FRONTIER Version 4.1: A computer program for stochastic frontier production and cost function estimation. CEPA working paper no. 7/96, University of New England, Armidale, NSW-2351, Australia.

De Datta, S. K., K. A. Gomez, R. W. Herdt and R. Barker. 1978. A handbook on the methodology for an integrated experiment - Survey on rice yield constraints. The International Rice Research Institute, Los Banos, Laguna, Philippines. Pp 60.

Fisher, R. A. 1958. Statistical Methods for Research Workers (Thirteenth edition), Section 21. Oliver and Boyd, Edinburgh, U.K. Pp 356.

Hasan, M. K. 2006. Yield gap in wheat production: A perspective of farm specific efficiency in Bangladesh. Ph.D. dissertation, Dept. of Agricultural Economics, BAU, Mymensingh. 
Hasan, M. K., M. J. Uddin, M. N. A. Khan, Q. Naher and M. A. H. Khan. 2002. Input use efficiency and profitability of pond fish culture in a selected area of Bangladesh. Bangladesh Journal of Fisheries 25 (1 \&2): 107-114.

Islam, M. H. 2003. Profitability and technical efficiency of wheat production in some selected areas of Dinajpur district. M. S. thesis, Dept. of Agricultural Economics, Bangabandhu Sheikh Mujibur Rahman Agricultural University, Gazipur, Bangladesh.

Islam, M. R. 2002. Determinants of production of and demand for rice in Bangladesh: A comparative study of aromatic and coarse varieties. Ph. D. dissertation, Dept. of Agricultural Economics, Bangladesh Agricultural University, Mymensingh-2202, Bangladesh.

Karim, M. R. 1996. Optimal crop-livestock farming in dry land (High Barind) area of Bangladesh. Ph.D. dissertation, Dept. of Agricultural Economics, BAU, Mymensingh-2202, Bangladesh.

Khan, M. A. and M. F. Alam. 2003. Technical efficiency of the hatchery operators in fish seed production farms in two selected areas of Bangladesh. Bangladesh Journal of Agricultural Economics, 26 (1\&2): 55-70.

Liewelyn, R. V. and J. R. Williams. 1996. Nonpararnetric analysis of technical, pure technical and scale efficiencies for food crop production in East Java, Indonesia. Agricultural Economics 15(2): 113-126.

Miah, T. H. 2001. Closing the yield gap and improving rice production efficiency in Bangladesh: A case of low-lying agriculture. Report submitted to International Rice Research Institute, Philippines. Dept. of Agricultural Economics, Bangladesh Agricultural University, Mymensingh-2202, Bangladesh. p 70.

Parikh, A. and K. Shah. 1994. Measurement of technical efficiency in the North-West Frontier Province of Pakistan. Journal of Agricultural Economics 45 (1): 132-138.

Rahman, K. M. M. 2002. Measuring efficiency of producing rice in Bangladesh: A stochastic frontier analysis. Ph.D. dissertation. Institute of Agricultural Policy and Marketing Research, Justus-Liebig University, Giessen, Germany.

Rahman, K. M. M., P. M. Schmitz and T. C. Wronka. 1999. Impact of farm-specific factors on the technical inefficiency of producing rice in Bangladesh. Bangladesh Journal of Agricultural Economics 22 (2): 19-41.

Rahman, K. M. M., P. M. Schrnitz and T. C. Wronka. 2000. A translog stochastic production frontier analysis on the estimation of technical efficiency of rice production in Bangladesh. Journal of Business Administration, 26(2\&3): 15-46.

Rajasekharan, P. and S. Krishnamoorthy. 1999. Technical efficiency of natural rubber production in Kerala: A panel data analysis. Indian Journal ofAgricultural Economics 54 (4):545-553.

Sharma, K. R., P. S. Leung and H. M. Zaleski. 1999. Technical, allocative and economic efficiencies in swine production in Hawaii: a comparison of parametric and nonparametric approaches. Agricultural Economics, 20 (1): 23-35.

Wilson, P., D. Hadley, S. Ramsden and I. Kaltsas. 1998. Measuring and explaining technical efficiency in UK potato production. Journal of Agricultural Economics 49 (3): 294- 305. 